\title{
Coexistence of Gastric Gastrointestinal Stromal Tumor and Ulcerative Colitis in Patient with Dyspepsia and Rectorrhagia: A Case Report
}

\author{
Ahmad Hormati $^{1}$ (D), Seyed Saeed Sarkeshikian ${ }^{1}$ (D), Faezeh Alamiyan ${ }^{1}$, Abolfazl Iranikhah ${ }^{1}$ (D), \\ Mahdieh Ghodoosi $^{2}$ (D), Mohammad Gharehbeglou ${ }^{1}$, Maryam Jameshorani ${ }^{3,4}$ (D), \\ Mohammad Reza Ghadir ${ }^{*}$ (iD
}

1. Gastroenterology and Hepatology Disease Research Center, Qom University of Medical Sciences, Qom, Iran

2. Dept. of Pathology, Qom University of Medical Sciences, Qom, Iran

3. Dept. of Internal Medicine, School of Medicine Vali-e-Asr Hospital Zanjan University of Medical Sciences, Zanjan, Iran

4. Metabolic Diseases Research Center, Zanjan University of Medical Sciences, Zanjan, Iran

\begin{tabular}{|c|c|}
\hline Article Info & ABSTRACT \\
\hline doi $10.30699 /$ jambs.27.120.51 & \multirow{5}{*}{$\begin{array}{l}\text { A } 32 \text {-year-old man with dyspepsia and rectorrhagia dating back } 3 \text { weeks underwent } \\
\text { endoscopy and colonoscopy. Upper GI endoscopy revealed a } 2 \times 2 \mathrm{~cm} \text { submucosal } \\
\text { lesion at the gastric body. Endoscopic ultrasonography confirmed GIST and surgery } \\
\text { was recommended. Colonoscopy diagnosed left side inflammatory bowel disease } \\
\text { (IBD) (ulcerative colitis). Abdominal CT scan and sonography had no apparent } \\
\text { abnormality. The pathology report confirmed low grade, spindle type gastrointestinal } \\
\text { stromal tumor (GIST). Treatment was started with oral Mesalazine and Asacol } \\
\text { enema. As the abdominal and pelvic CT showed no metastasis, a complete surgical } \\
\text { resection of the tumor was performed and in a 6-month follow up, the patient had no } \\
\text { problem. IBD patients are at an increased risk of malignancy due to chronic } \\
\text { inflammatory state and the use of immunomodulator agents. Thus, the risk of } \\
\text { malignancies at the beginning of the disease is low and its occurrence is rare. The } \\
\text { most common cancer in such patients is adenocarcinoma and GIST is somehow rare, } \\
\text { with a small number reported in literature. Since the presence of GIST is not related } \\
\text { to disease activity, it should be considered in differential diagnosis in patients with } \\
\text { controlled IBD who are still symptomatic. } \\
\text { Keywords: GIST, IBD, Ulcerative Colitis }\end{array}$} \\
\hline $\begin{array}{c}\text { Received: 2018/02/18; } \\
\text { Accepted: 2018/07/31; } \\
\text { Published Online: 01 Jan 2019; }\end{array}$ & \\
\hline $\begin{array}{l}\text { Use your device to scan and read the } \\
\text { article online }\end{array}$ & \\
\hline \multirow{2}{*}{$\begin{array}{l}\text { Corresponding Information: } \\
\text { Mohammad Reza Ghadir, } \\
\text { Gastroenterology and Hepatology Disease } \\
\text { Research Center, Qom University of } \\
\text { Medical Sciences, Qom, Iran } \\
\text { Email: ghadir1968@ gmail.com }\end{array}$} & \\
\hline & \\
\hline & \\
\hline
\end{tabular}

\section{Introduction}

Gastrointestinal Stromal Tumors (GIST) are mesenchymal tumors of gastrointestinal tract, accounting for $1 \%$ of all GI tumors. $(1,2)$. The most common site for developing GIST is stomach and proximal part of the small intestine, but it may occur in any part of GI tract and also peritoneal cavity and omentum. Most of these tumors discover accidentally during endoscopic or radiologic studies. Common clinical presentation is non-specific upper GI symptoms including bloating or early satiety, but in some cases the tumor is large enough to cause obstruction (3).

Inflammatory bowel disease (IBD) including Crohn's disease and ulcerative colitis are chronic inflammatory disorders with a growing prevalence in Iran. The disease develops by immunologic reaction to normal GI flora in genetically susceptible individuals. (4). Previous studies have shown that patients with IBD are at an increased risk for malignancies, especially adenocarcinoma. This increased risk may be due to the inflammatory and chronic nature of the disease, or due to the immunomodulatory drugs which are used to control the disease, including thiopurines and biologic agents (4, 5). Although occurrence of adenocarcinoma in IBD patients is not unexpected, but developing other tumors, including GIST, especially in early stages of the disease is not common (6).

This article introduces a rare case of a young man with a 2week history of dyspepsia and rectorrhagia who was diagnosed as having both ulcerative colitis and gastric GIST at the same time.

\section{Case Report}

A 32 year-old man referred to the gastroenterology clinic, complaining from dyspepsia and post-prandial discomfort for 3 weeks. He also mentioned rectorrhagia within the last 10 days. The patient complained of malaise. He did not mention nausea, vomiting, abdominal pain, any changes in bowel habits or weight loss. In his past medical history, he did not mention symptoms of a minor depression. He didn't take any medications. He was not a smoker or an alcohol consumer. 


\section{He Looked Ill and His Vital Signs Were as Below}

Blood pressure: 110/60 $\mathrm{mmHg}$, pulse rate: 79 per minute, respiratory rate: 16 per minute and body temperature from oral root: $37.4^{\circ} \mathrm{C}$.

During physical examination, his abdomen was not distended and was soft with no tenderness in palpation. The rest of examinations were unremarkable.
The patient underwent an upper GI endoscopy, which revealed a $2 \times 2 \mathrm{~cm}$ submucosal lesion (Figure 1) at the gastric body, and Endoscopic Ultrasound (EUS) was recommended. The EUS revealed a $22 \times 20 \mathrm{~mm}$ hypoechoic lesion in the midportion of lesser curvature that originates from the muscularis propria layer with some cystic degeneration. No regional lymphadenopathy was detected. The pancreas and biliary systems looked normal (Figure 2). With a suspension of stromal tumor, surgery was recommended.

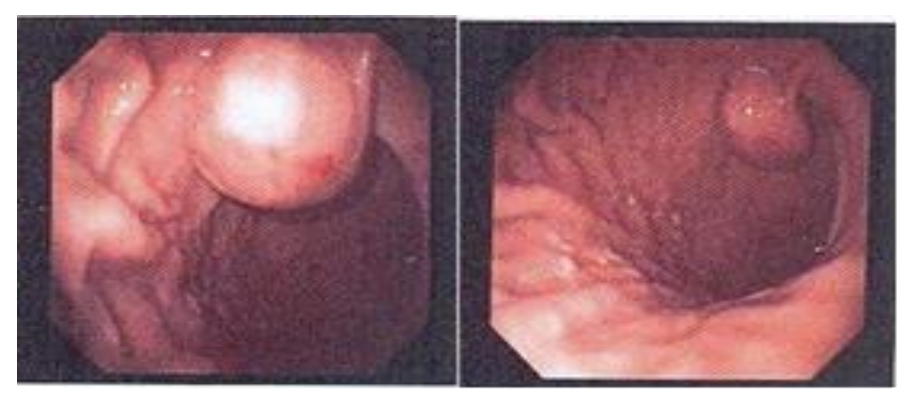

Figure 1. Endoscopy of the patient
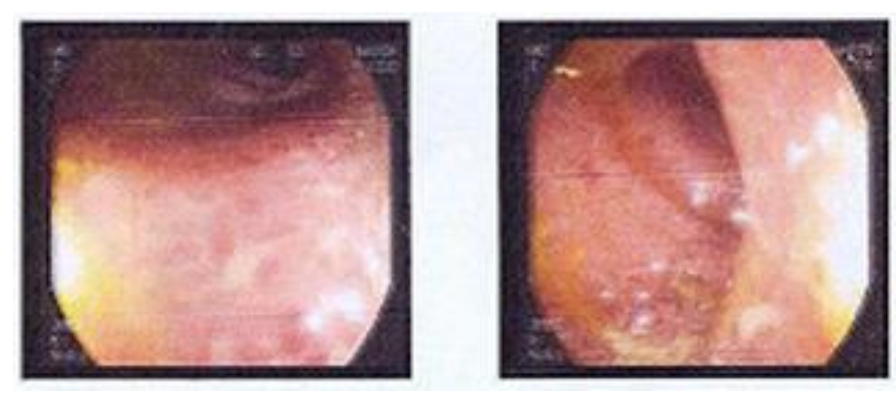

Figure 2. Colonoscopy of the patient

Colonoscopy up to the descending colon demonstrated exudate, bleeding and mucosal erythema in the rectum, sigmoid and descending colon (Figure 3). A biopsy was taken and a pathological study revealed ulcerative colitis (Figure 4).

An abdominal spiral CT scan with triphasic protocol of the liver and oral and IV contrast was performed and no apparent abnormality was detected.

Then, the patient underwent surgery, and a pathological study of the gastric lesion revealed a wellcircumscribed intramural mass composed of sheets of spindle cells with minimal pleomorphism. The mitotic activity was 1-2 mitoses per 50 high-power fields (1$2 / 50 \mathrm{HPF}$ ). The final diagnosis of the lesion was a low grade, spindle type GIST with very low risk of progressive disease, and pathological tumor-nodemetastasis (pTNM) staging was pT2 (the tumor has grown into the muscularis propria, the muscle layer of the stomach), NX (Regional lymph nodes cannot be evaluated) and MX (Distant metastasis cannot be evaluated) (Figure 5).

Treatment was initiated with oral Mesalazine (5aminosalicylic acid) and Asacol enema. Since the tumor was classified as low risk, no systemic chemotherapy was given. As the abdominal and pelvic CT showed no metastasis, a complete surgical resection of the tumor was performed and due to low Ki67 levels and no metastasis, Imatinib was not prescribed. In a 6-month follow up, the patient had no problem. 

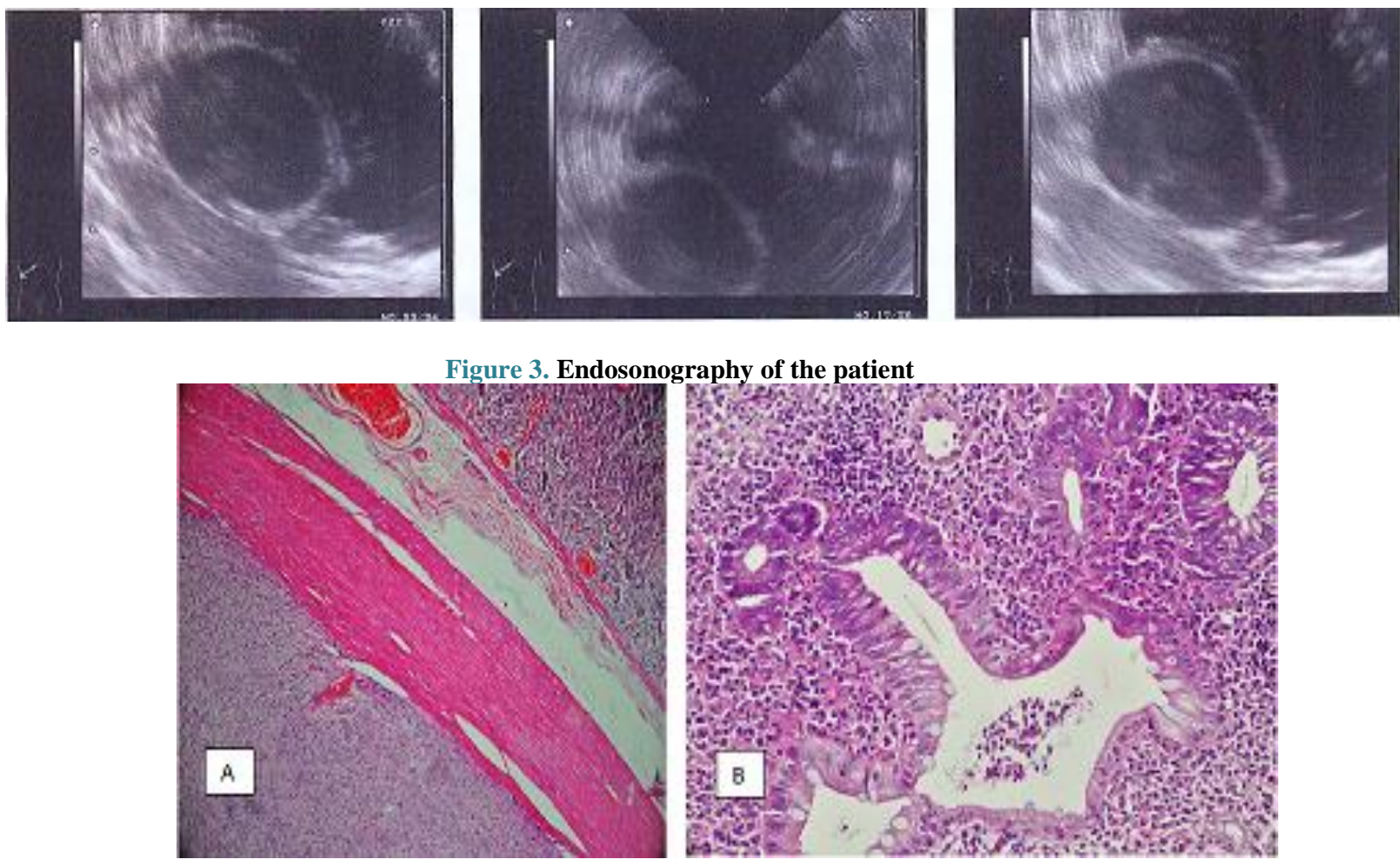

Figure 4. A: Well-circumscribed intramural mass. B: Architectural crypt distortion, cryptitis and crypt abscess

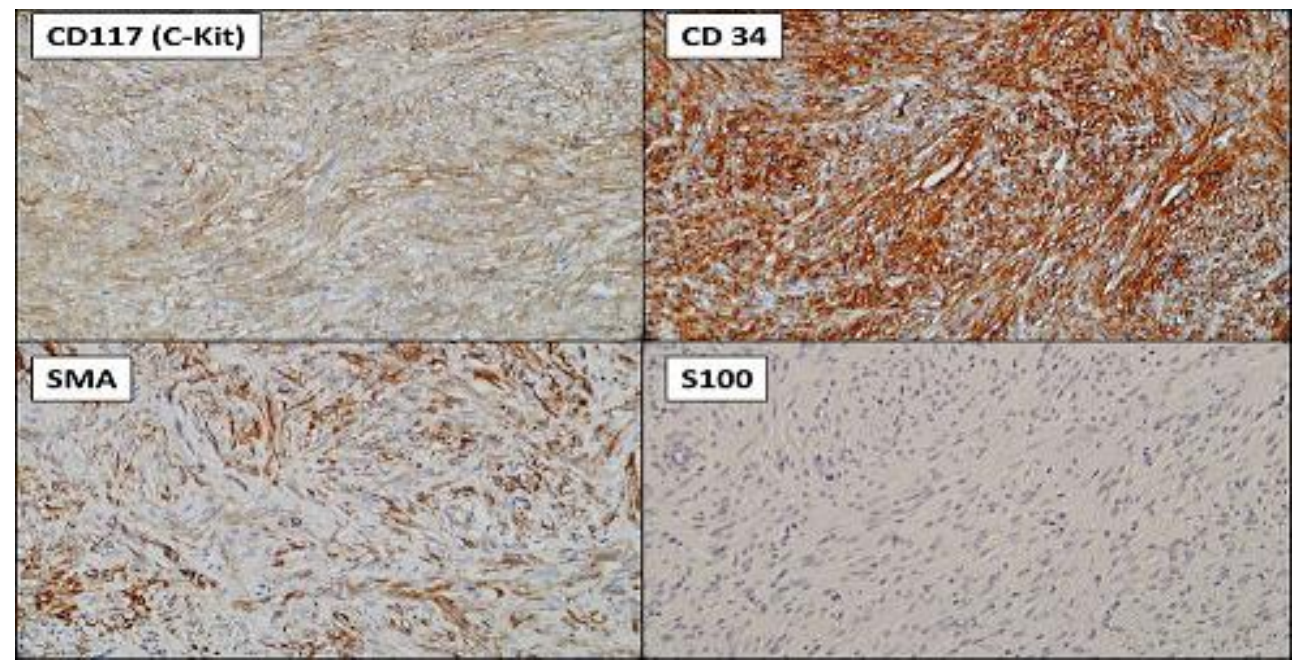

Figure 5. Tumor cells are diffusely positive for C-kit and CD 34, partially positive for SMA and are negative for $\mathrm{S100}$

\section{Discussion}

An important issue in the management of IBD is the risk of malignancies, which is mostly reported in patients receiving prolonged immunosuppressive therapy or biological agents and are rare at the initiation of the disease (7). A prolonged inflammatory state is a risk factor for the progression of malignant lesions too. The most common cancer in IBD patients is adenocarcinoma. $(8,9)$.

GISTs, are among rare tumors in IBD patients, and there are few reports of such cases $(6,10)$. The most common site of involvement is the stomach, following by the jejunum, ileum, duodenum and colon. Previous studies demonstrated that the risk of the incidence of GIST is not related to IBD activity; so, in IBD patients who are symptomatic and have no evidence of disease reactivation, GIST should be considered in the differential diagnosis (11).

The treatment of choice for GIST is surgical resection. The tumor should not be opened because of the risk of peritoneal dissemination. Lymph node involvement is not common. 
In our patient, endoscopic findings, as well as clinical evaluations, confirmed the diagnosis of UC, and GIST had no symptoms. Most GIST cases with IBD have a long history of IBD prior to the development of malignancy $(12,13)$.

In managing of IBD patients, investigating for probable malignancies is a key point for early diagnosis and improve the outcomes of the disease (14). The coincidence of UC and GIST is extremely rare. Grieco et al. reported a 57-year-old woman affected by UC in remission, whose abdominal CT scan revealed GIST in the upper left pelvic cavity (15). So, in cases with IBD diagnosis, GIST should be considered in further evaluation and differential diagnosis.

\section{Acknowledgements}

The authors thank all those who helped them writing this paper.

\section{Conflict of Interest}

Authors declared no conflict of interests.

\section{References}

1. Steigen SE, Eide TJ. Gastrointestinal stromal tumors (GISTs): a review. APMIS. 2009; 117: 73-86. [DOI:10.1111/j.1600-0463.2008.00020.x] [PMID]

2. Katz SC, DeMatteo RP. Gastrointestinal stromal tumors and leiomyosarcomas. J Surg Oncol. 2008; 97: 350-9. [DOI:10.1002/jso.20970] [PMID]

3. Medeiros F, Corless CL, Duensing A, et al. KIT-negative gastrointestinal stromal tumors: proof of concept and therapeutic implications. Am J Surg Pathol. 2004; 28: 88994. [DOI:10.1097/00000478-200407000-00007] [PMID]

4. Colombel JF, Sandborn WJ, Reinisch W, et al. Infliximab, azathioprine, or combination therapy for Crohn's disease. $\mathrm{N}$ Engl J Med. 2010; 362: 1383-95. [DOI:10.1056/NEJMoa0904492] [PMID]

5. Ransofoff DF: Colon cancer in ulcerative colitis. Gastroenterology. 1998; 94: 1089-91 [DOI:10.1016/00165085(88)90573-2]

6. Pfeffel F, Stiglbauer W, Depisch D, Oberhuber G, Raderer M, Scheithauer W. Coincidence of Crohn's disease and a high-risk gastrointestinal stromal tumor of the terminal ileum. Digestion. 1999; 60(4): 363-6. [DOI:10.1159/000007684] [PMID]

7. Toader E, Ciortescu I. Is there a risk for lymphoma or extracolonic cancer in patients with inflammatory bowel disease? Rev Med Chir Soc Med Nat Iasi. 2013; 117(2): 36874.

8. Hormati A, Ghadir MR, Sarkeshikian SS, et al. Coexistence of crohn's disease and hodgkin's lymphoma in a young man with rectorrhagia. Jundishapur J Chronic Dis Care. 2017; 6(2): e42794. [DOI:10.5812/jicdc.42794]

9. Ruffolo C, Massani M, Rossi S, Caratozzolo E, Antoniutti $\mathrm{M}$, Bassi N. Adenocarcinoma and GIST in ulcerative colitis. Int J Colorectal Dis. 2010; 25(8): 1027-8. [DOI:10.1007/s00384-010-0905-x] [PMID]

10. Mijandrusić Sincić B, Kovac D, Jasić M, Grbas H, Uravić M, Depolo A. Crohn's disease and a gastrointestinal stromal tumor in an 81-year-old man-a rare coincidence. Zentralbl Chir. 2005; 130: 597-99. [DOI:10.1055/s-2005-918206] [PMID]

11. Pellino G1, Marcellinaro R2, Candilio G3, et al. The experience of a referral centre and literature overview of GIST and carcinoid tumours in inflammatory bowel diseases. Int J Surg. 2016; 28: S133-41. [DOI:10.1016/j.ijsu.2015.12.051] [PMID]

12. Stahl TJ, Schoetz DJ, Roberts PL, Coller JA, Murray JJ, Silverman MC, Veidenheimer MC. Crohn's disease and carcinoma: Increased justification for surveillance? Dis Colon Rectum. 1992; 35: 850-6. [DOI:10.1007/BF02047872] [PMID]

13. Laukhuf F, Tischer KH, Strobel K, Wietholtz H. Crohn's disease and stromal sarcoma of the small bowel- a rare coincidence. Zeitschrift fur Gastroenterologie. 2002; 40(3): 193-6. [DOI:10.1055/s-2002-22320] [PMID]

14. Vassos N, Agaimy A, Hohenberger W, Croner RS. Coexistence of gastrointestinal stromal tumours (GIST) and malignant neoplasms of different origin: prognostic implications. Int $\mathbf{J}$ Surg. 2014; 12(5): 371-7. [DOI:10.1016/j.ijsu.2014.03.004] [PMID]

15. Grieco A, Cavallaro A, Potenza AE. Gastrointestinal stromal tumor (GIST) and ulcerative colitis. J Exp Clin Cancer Res. 2002; 21(4): 617-20. [Article] [PMID]

\section{How to Cite This Article:}

Hormati A, Sarkeshikian S S, Alemi F, Iranikhah A, Ghodoosi M, Gharehbeglou M, et al . Coexistence of Gastric Gastrointestinal Stromal Tumor and Ulcerative Colitis in Patient with Dyspepsia and Rectorrhagia: A Case Report. J Adv Med Biomed Res. 2019; 27 (120) :51-54

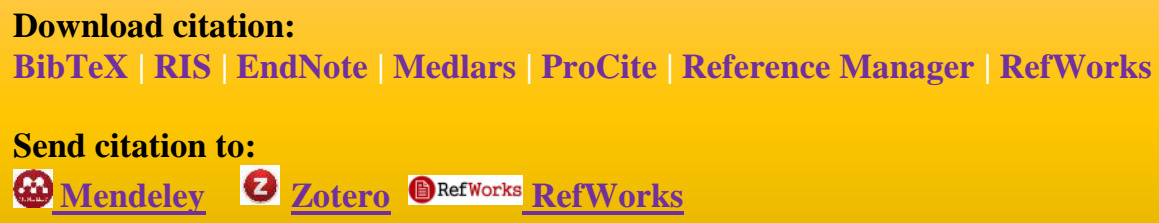

